\title{
ANALYZING USE OF THANKS TO YOU: INSIGHTS FOR LANGUAGE TEACHING AND ASSESSMENT IN SECOND AND FOREIGN LANGUAGE CONTEXTS
}

\author{
BETTY LANTEIGNE \\ American University Of Sharjah \\ blanteigne@aus.edu \\ PETER CROMPTON \\ American University Of Sharjah
}

\begin{abstract}
This investigation of thanks to you in British and American usage was precipitated by a situation at an American university, in which a native Arabic speaker said thanks to you in isolation, making his intended meaning unclear. The study analyzes use of thanks to you in the Corpus of Contemporary American English and the British National Corpus to gain insights for English language instruction /assessment in the American context, as well as English-as-a-lingua-franca contexts where the majority of speakers are not native speakers of English or are speakers of different varieties of English but where American or British English are for educational purposes the standard varieties. Analysis of the two corpora revealed three functions for thanks to you common to British and American usage: expressing gratitude, communicating "because of you" positively, and communicating "because of you" negatively (as in sarcasm). A fourth use of thanks to you, thanking journalists/guests for being on news programs/talk shows, occurred in the American corpus only. Analysis indicates that felicitous use of thanks to you for each of these meanings depends on the presence of a range of factors, both linguistic and material, in the context of utterance.
\end{abstract}

Key words: thanks to you, pragmatic failure, Arabic, expression of gratitude, American and British English corpora, language teaching and testing

\section{Introduction}

On three occasions at a university in the USA, the first author observed a native Arabic speaker apparently attempting to express gratitude to fellow graduate students who had helped him earlier. On all three occasions the interaction was as follows:

[Setting: Male and female graduate students from Asia, Africa, the Middle East, and North America speaking together outside of the classroom. Some of them have just done a favor for S1.] 
S1:

Other Ss:

"Thanks to you" [smiling]. Leaves

[silence]

S1, a native Arabic speaker, was very likely transferring to English a translation of a polite expression such as shukran lakum in classical Arabic used to express gratitude, literally meaning thanks to you, yet this transfer resulted in pragmatic failure (Thomas, 1983), as evidenced in the response of silence by all of the interlocutors on all three occasions, silence which to an observer seemed obviously socially awkward. There were no replies such as you're welcome, don't mention it, or glad to have helped, etc., which would have been typical responses to an expression of gratitude in this American setting. In international settings as well, such as with use of English as a lingua franca in the Arabian Gulf, gratitude responses would be commonly expected.

Several years later, during presentations at two conferences (Lanteigne 2007; 2009) in the Arabian Gulf using this anecdote as an example of pragmatic failure, comments from native English speakers in the audience (from the USA, Australia, and the UK) indicated that they viewed thanks to you as always being a sarcastic expression. Their opinions as to whether or not it could be a very formal expression of gratitude were mixed. Native English speakers in one conference discussion group agreed that expressions such as "I would like to express my most sincere thanks to you" were possible but were very formal and would only be used in writing, while at the second conference discussion native English speakers felt that thanks to you would not be used even formally. Instead, in their estimation, "I would like to express my most sincere gratitude/appreciation to you" would be used. Comments by native Arabic speakers from various Arab countries in the Middle East in these same conference discussions revealed that they were unfamiliar with the sarcastic meaning of thanks to you and were shocked to hear that what was a very polite expression in Arabic could be interpreted so differently - and negatively - when translated to English.

These incidents raised questions about the use of this expression: how is thanks to you used in contemporary American English (which was the original context of this problematic use of thanks to you), both in academic and other settings? Is thanks to you always sarcastic? Does the expression typically precede or follow the reason for thanking, and is this positioning systematically related to whether the gratitude is intended sincerely or ironically? In terms of effective intercultural communication in English-as-a-lingua-franca (ELF) settings where the majority of speakers are not native speakers of English but speakers of different varieties of English, how should use of thanks to you be viewed? What insights can corpus analysis offer about teaching and testing use of thanks to you with English language learners, both in the USA and in lingua franca situations?

Investigation addressing these questions involved analyzing uses of thanks to you in two American English corpora [the 1.8 million word Michigan Corpus of Academic Spoken English (The University of Michigan English Language Institute, 2007) and the 400 million word Corpus of Contemporary American English (Davies, 2008-)], and comparison with use of the phrase in the 100 million word British National Corpus (Davies, 2004-). American and British usages of thanks to you were explored because of the wide international use of these two English dialects, both separately and in combination, in ELF communication in regions such as the Arabian Gulf. 


\section{Previous research}

\subsection{Gratitude in context}

According to Kasper and Rose (2001), expression of gratitude is an individual communicative act which is present in communities around the world. Specifically concerning communication in English, Singh, Lele, and Martohardjono (2005) point out the importance in English of thanking and the great potential for cross-cultural miscommunication in language learners' inappropriate expressions of gratitude. Appadurai (1985) describes such a cross-cultural challenge facing native English speakers learning Tamil and native Tamil speakers' learning English. Expression of gratitude in Tamil is indirect compared to Western languages, such as English, making translation of $I$ thank you into Tamil culturally problematic. Such non-equivalence can result in misconceptions about the extent of (or lack of) gratitude of non-native speakers when using the target language (Tamil or English). Intachakra (2004) compiled specialized corpora of thanking in Thai and in English and found a similar tendency toward inexplicitness in Thai. Eisenstein and Bodman (1986; 1993) also discuss challenges with expression of gratitude in English encountered by even advanced English language learners. Schauer and Adolphs (2006) found that in a corpus of spoken British English expressions of gratitude were often accompanied by other speech acts in formulaic sequences, such as "thanking + giving reason" (e.g., Thanks for coming), "thanking + confirming interlocutor's commitment (e.g. Are you sure? OK, thanks!). They also found extended turns (e.g., Oh right. Oh great stuff. That's brilliant. Thank you very much. That's much appreciated.) "a general rule in the corpus data rather than an exception" (2006: 131). By contrast, in a study of thanking by Hong Kong English speakers in the Hong Kong component of the International Corpus of English, Wong (2010) found a much reduced set of formulas and far fewer extended turns, again in her view based on a cultural tendency for thanking to be inexplicit in Chinese culture.

Searle (1969) describes thanking as an illocutionary act in which gratitude is being expressed by a speaker for an earlier beneficial action done by the hearer. According to Nofsinger (1999: 29), thanking is a speech act, specifically classified under expressives, which are "expressions of the speaker's psychological state about something (an event, an object, a behavior, or whatever)." However, the speech act of expressing gratitude is often followed by a response to the expression of gratitude, a conversational structure which constitutes an adjacency pair. Hutchby and Wooffit (1998: 39) define adjacency pairs as "pairs of utterances which are ordered, that is, there is a recognizable difference between first pair parts and second parts (or a particular range of seconds)." As an adjacency pair, expression of gratitude and the subsequent response function as an expressive speech act (Searle, 1969) in which the first pair part communicates gratitude and the second pair part responds to the expression of gratitude. Pointing out the importance of the presence of both aspects of an adjacency pair, Dippold (2008: 138) concludes that "a first pair part always makes a second pair part immediately relevant, and the absence of a second pair part is both noticeable and accountable (principle of conditional relevance: Schegloff 1968)." In the opening anecdote described above 
about the native Arabic speaker's use of thanks to you, it was the lack of response (the second pair part of the adjacency pair) that was quite notable as being socially marked.

A common expression of gratitude and gratitude response in English is the routine Thank you followed by You're welcome (Bonvillain, 1997). While there are numerous polite formulae in Arabic for expression of gratitude (Nelson, Al-Batal, \& Echols, 1998), one common adjacency pair is shukran followed by 'afwan, which are frequently translated as thank you and you're welcome (Alosh, 2000).

\subsection{Pragmatics instruction}

For language learners pragmatic competence is the "ability to act and interact by means of language" (Kasper and Roever 2005: 317). Thomas (1983) describes two aspects of pragmatic competence - sociopragmatic and pragmalinguistic - addressing crosscultural miscommunication which may occur as a result of pragmatic failure on the part of language learners. "'Sociopragmatic' knowledge describes knowledge of the target language community's social rules," while "“pragmalinguistic' knowledge encompasses the linguistic tools necessary to 'do things with words' (Austin 1962)" (McNamara and Roever 2006b: 55), although these two aspects of pragmatics overlap considerably. According to Thomas (1983), pragmalinguistics refers more to rules about language form, as in syntax or grammar, rather than social rules about appropriate behavior. It is possible for an utterance to be grammatically correct but socially inappropriate, as in greeting a future employer in a formal interview with "What's up?" (a sociopragmatic error). In contrast, a pragmalinguistic error would involve making a grammatical choice with social implications different from those intended. An example of a pragmalinguistic error which occurred to one of the authors was when a fellow conference delegate, as part of a preliminary to asking for a ride, inquired "Do you drive?" The author, not recognizing the question as a preliminary to a request for a favor replied "yes". The inquirer then made the request and was surprised to learn that the author could not accommodate her as she did not have her car with her. Had the inquirer used the past tense, "Did you drive?" her interlocutor would have recognized the question as a preliminary and explained that she could not offer the speaker a ride: use of the present rather than the past tense was in this case responsible for the miscommunication.

In the opening anecdote, negative language transfer from Arabic is a likely contributing factor to the miscommunication, according to Rana Raddawi, EnglishArabic-English translation specialist (personal communication, 2010). Raddawi explains that in classical Arabic the expressions shukran lakum or shukran laka or shukran laki would be appropriate expressions of gratitude reflecting plural, masculine singular or feminine singular forms, respectively, of you, and could be literally translated as thanks to you.

\subsection{Corpus studies and language learning}

This present study uses analysis of American English in the Corpus of Contemporary American English (Davies, 2008-), hereafter COCA, to investigate use of thanks to you 
in the American context. It also looks at thanks to you in the British National Corpus (Davies, 2004-), hereafter BNC, for comparison of these two major English dialects' usage. The purpose of comparing American and British usage is to gain insights for English language instruction and assessment in English-as-a-lingua-franca (ELF) settings where the majority of speakers are not native speakers of English or are speakers of different varieties of English.

Use of language corpora for language learning was pioneered by Johns (1991) who initially proposed corpora analysis as a means of data-driven learning by language learners. Also, two uses of corpora in language teaching, according to Hunston (2002), are as raw data in a corpus-based syllabus, and as a source of selected examples to teach targeted aspects of language. Gesuato (2007) describes using analysis of texts carefully selected from a language corpus to develop awareness of semantic distinctions among English near-synonyms. She found that foreign language students "can be sensitized to the context specificity of each near synonym, which may encourage their correct use of terms" (188). Gesuato also found that corpora can reveal more unusual uses of phrases not included in dictionaries.

According to Hunston (2002), language obtained through corpora has the advantage of being authentic and reveals uses that native speakers do not think of. As an example of this, Schauer and Adolphs (2006) compared their corpus research data with the descriptions of thanking found in various instruction materials - presumably based on native speaker intuition - and found both the range of linguistic realizations and of formulaic sequences for thanking much smaller than that revealed in the corpus data. However, there are disadvantages to the use of language corpora in language teaching. Hunston (2002) points out that use of corpora in language teaching is time-consuming. It takes time to search the corpus (for the teacher and/or students), and it takes class time to discuss the texts found in a corpus. In addition, Hunston points out that not all uses of an expression in the corpora are grammatically correct since the texts reflect what people actually say. Thus teachers must evaluate texts obtained from corpora for correctness and appropriateness. Along with the expense of collecting spoken data, this consideration may have led to a somewhat narrow emphasis on written academic texts in the literature on applying corpus research to language instruction. In a recent review of such literature, Keck observes "corpus-based research that addresses a wider range of learner proficiencies and goals is greatly needed" (2004: 91).

Partly because of an emphasis, following John's data-driven learning lead, on discovery learning and partly because of rival approaches to language description (Keck 2004: 93), the range of corpus-based language instruction materials currently readily accessible for language teacher use is small. Reinhardt (2010: 239) says,

The future of corpus in L2 pedagogy depends on the extent to which [second language acquisition] research and [pedagogical] innovation can impact professional L2 instructor education and the design of commercial L2 teaching materials, as well as the continuing development of corpora and corpus-informed resources that are accessible, diverse, and adaptable. 


\subsection{Pragmatics assessment}

In terms of language assessment, Bachman and Palmer (1996) indicate that there is a three-fold relationship between real-world target language use, instruction, and assessment; in their test development model Bachman and Palmer include pragmatic competence as an aspect of communicative ability in language use. Kasper and Rose (2001) point out that "in instructional contexts where formal testing is regularly performed, curricular innovations that comprise pragmatics as a learning objective will be ineffective as long as pragmatic ability is not included as a regular and important component of language tests" (9). McNamara and Roever (2006a) indicate that, while there are challenges with assessment of pragmatic ability, pragmatic competence is an integral aspect of effective communication in learning a language which should be included in language assessment.

To summarize, the current study seeks to use English language corpora to identify and analyze uses of thanks to you in American and British English to provide insight for English language instruction and assessment on use of this expression, both in American contexts and in international communication.

\section{Data identification}

\subsection{Academic spoken English: Corpus evidence for thanks to you}

First, as the anecdote described above took place in an academic setting in the USA, the 1.8 million-word Michigan Corpus of Academic Spoken English (MICASE) was searched for use of thanks to you, using the widest possible search parameters, including gender, age, speech event, academic division, participant level, and interactivity. Native speakers of American English and other Englishes were included in the search parameters, and the search of this corpus revealed no uses of thanks to you.

Next searched was the BNC, which contains 1.6 million words of text categorized within the domain "spoken context-governed, educational/informative." A search of these texts also revealed no tokens of thanks to you. (COCA does not contain academic spoken texts as most of its spoken texts are taken from radio and TV broadcast transcripts.)

\subsection{General spoken English: Corpus evidence for thanks to you}

In order to investigate use of this expression in broader contexts and identify uses of thanks to you common to both major English dialects, uses which would thus be more likely to be appropriate in international communication, it was decided to search two large publicly available corpora of US and UK English. Search parameters for the COCA and the BNC were set to include spoken English and fiction, with speakers from all spheres of society and language backgrounds. Instances of thanks to you were only included in the counts for fiction if they appeared within dialogue. Fiction dialogues 
were included for analysis as it is assumed that these are written to reflect spoken communication. Nearly 400 tokens of the phrase were found.

\section{Data analysis}

\subsection{Overall frequency and function}

To give an idea of the relative frequency of the phrase the standardized frequencies of the occurrence of "thank you" and thanks to you in spoken and fiction components of COCA and the BNC are given in Table 1. Occurring at around 1\% of the frequency of thank you, thanks to you is clearly relatively exotic.

\begin{tabular}{|l|l|l|l|l|}
\hline & \multicolumn{2}{|l|}{ COCA } & \multicolumn{2}{l|}{ BNC } \\
\hline & Spoken & Fiction & Spoken & Fiction \\
\hline Thank you & 742.6 & 116.37 & 585.4 & 157.9 \\
\hline Thanks to you & 2.83 & 1.6 & 0.3 & 2.7 \\
\hline
\end{tabular}

Table 1 Standardized frequencies (per million words) of phrases in corpora

In the Fiction and Spoken subcorpora of COCA, a total of 357 tokens of thanks to you were retrieved. Analysis of these revealed that five were duplicates. These were removed, as well as five tokens of thanks to you which were deemed not to represent spoken English, such as uses in a song, a prayer, and a letter read aloud. This left a total of 347.

An analysis of function in these tokens suggested that there were two major functions: (a) to express gratitude to the addressee and (b) to state that a given state of affairs was "because of" the addressee. Out of the 347 American tokens analyzed, 216 expressed gratitude, 197 appearing in a form apparently unique to radio and television broadcasts, 19 in other contexts, and 131 communicated primarily the meaning "because of you" (see Table 2).

\begin{tabular}{|l|l|l|l|l|}
\hline & \multicolumn{2}{|l|}{ Gratitude } & $\begin{array}{l}\text { "Because of } \\
\text { you" }\end{array}$ & Combined \\
\hline & $\begin{array}{l}\text { Broadcast } \\
\text { formula }\end{array}$ & Other & & \\
\hline $\begin{array}{l}\text { Fiction } \\
\text { dialogue }\end{array}$ & 0 & 14 & 105 & 119 \\
\hline Spoken & 197 & 5 & 26 & 228 \\
\hline Total & $\mathbf{1 9 7}$ & $\mathbf{1 9}$ & $\mathbf{1 3 1}$ & $\mathbf{3 4 7 *}$ \\
\hline
\end{tabular}

* = after removal of duplicates and nonstandard spoken tokens

Table 2 Classification of thanks to you tokens in COCA 
In the BNC spoken and fiction (dialogue) texts there were 44 tokens of thanks to you. There were no uses of thanks to you as a broadcast formula expressing gratitude, but there were three uses to express gratitude and 41 tokens meaning "because of you" (see Table 3).

\begin{tabular}{|l|l|l|l|l|}
\hline & \multicolumn{2}{|l|}{ Gratitude } & $\begin{array}{l}\text { "Because of } \\
\text { you" }\end{array}$ & Combined \\
\hline & $\begin{array}{l}\text { Broadcast } \\
\text { formula }\end{array}$ & Other & & \\
\hline Fiction dialogue & 0 & 3 & 39 & 42 \\
\hline Spoken & 0 & 0 & 2 & 2 \\
\hline Total & $\mathbf{0}$ & $\mathbf{3}$ & $\mathbf{4 1}$ & $\mathbf{4 4}$ \\
\hline
\end{tabular}

Table 3 Classification of thanks to you tokens in BNC

\subsection{Thanks to you as a broadcast formula to express gratitude}

Contrary, then, to the claim by some of the native English speakers in the conference group discussions mentioned above that thanks to you would not be used to express gratitude, both the COCA and the BNC revealed use of thanks to you to express gratitude.

There were 197 uses of thanks to you from COCA spoken corpus which appeared to be "self-standing formulas" expressing gratitude. These consisted of salutations at the beginning or end of a news program or talk show, thanking either guests/journalists on the show for coming or the audience for joining them, statements such as the following (examples 1-2):

1. "We appreciate you being here, David Sirota. Terry Holt, thanks to you, too" (SPO: Fox)

2. "We want to thank all our guests tonight for their insights. Thanks to you at home for tracking these cases with us" (SPO: CNN)

Common patterns involved prefixing thanks to you with our (41 instances) and my (7 instances), as in the following examples:

3. "All right. Our thanks to you David Shipley, USAir spokesman, and we'll be back with more" (SPO: ABC_Pr)

4. "My thanks to our panel. My thanks to you, our viewers. We'll be back again the same time next" (SPO: CNN_Reliable)

As examples 1 to 4 suggest, unlike spontaneous expressions, these expressions of gratitude often serve as discourse boundary markers. It is also notable that these expressions were always accompanied by clear designations of the individual or group 
(guests/journalists/viewers) who were being thanked for being part of the program. It appears that the formulaicity and the formality of these tokens is an artifact of the broadcasting situation, in which there is a possible ambiguity as to the intended addressee of the gratitude because there are at least three discourse participants - (i) the studio guest(s) or reporter(s), (ii) the audience at home, and (iii) the mediating anchor or host. The gratitude the anchor/host expresses appears to be public rather than private, in that it is expressed in the presence of others, and at least in part on behalf of a third party, either the third participant (guest/reporter or audience) or those responsible for the show (producers, network etc). In non-broadcast, two-handed dialogues there is clearly no need to disambiguate the addressee of the gratitude being expressed, nor is there necessarily an audience.

\subsection{Thanks to you to express gratitude outside the broadcast formula}

There were 20 instances from COCA in which thanks to you was used to express gratitude outside use of the parameter of the broadcast formula described above. Six of these instances appeared in broadcasting contexts, while the remaining 14 were from fiction dialogue.

In twelve cases, these expressions of gratitude were similar to broadcast formula thanks to you in that they were also "freestanding", e.g., in that they were not a constituent part of larger syntactic unit, such as a verb phrase. (See examples 5 and 6.)

5. "I'll get the Egg's protocols started up." Govanek said, "Thanks to you both." Mike had made sure to land in an area where (FIC: Analog Science Fiction and Fact)

6. "I will have it prepared for you, Ms. MacInnes, and our thanks to you for your help. My SAR team is understaffed, all but myself' (FIC: Bk CatchThief)

Like the broadcast formula these two examples are accompanied by recipientdesignating expressions, both and Ms. MacInnes. A fuller inspection of the context of example 5 reveals that the speaker in this case is actually addressing two interlocutors, one in the same place, the other remote but in contact via an intercom; this dual audience situation replicates that of the anchor in the broadcast formulas discussed earlier.

Some of the "free-standing" tokens appear, like example 5, in science fiction or historical fiction such as the following:

7. He leaned forward and kissed her lightly on the cheek. "My thanks to you," he said, and tore himself away, returning to his (FIC: Bk: KnightsCaptive)

8. patched, and discharged to make room in the hospital. "The clan's thanks to you for your sacrifice." "Foremost," Lothwer interrupted. (FIC: Analog Science Fiction and Fact) 
One is tempted to think that this form (in examples 7 and 8) has been chosen for its archaic, old world or otherworldly quality. From a methodological perspective these instances show the limitations of including in a corpus of contemporary language literary representations of speech which may be deliberately intended to deviate from contemporary spoken norms.

Unlike these "freestanding examples" and the broadcast formula instances of thanks to you, the remaining seven of the COCA tokens of thanks to you do not constitute expressions of gratitude by themselves but are part of longer, extensive expressions of gratitude and carry illocutionary force only as constituents of clauses involving a performative verb phrase (e.g., phrases headed by expresss, extend, send) (see example 9.)

9. "Well, I just want to extend my thanks to you for doing this on short notice. Everybody at InGen appreciates it.” (FIC: BkSFi: JurassicPark)

Six such "non-freestanding" tokens appear in broadcast texts (see examples 10-11):

10. candidate approached the microphone stand. "I want to express my thanks to you as a graduate of the Michigan of the East, Harvard University." (SPO: NPR)

11. "please excuse my back. I just want to express a personal note of thanks to you for coming here this evening. I know there are an awful lot" (SPO: ABC Nightline)

One of them is in a dialect other than Modern Standard American (example 12):

12. "Kentucky. Yeah. That's the song. Give a big thanks to you. Where's y'all's big city at, yo." (SPO: NPR).

These longer performatives are presumably modern descendants of the full sentence forms such as I give thanks to you which, according to Jacobsson (2002:67), were more common than thank you and thanks in Early Modern English.

Turning to British English, as represented in the BNC, there are only three instances of thanks to you being used for expression of gratitude, all from fictional representations of informal speech. All three tokens have illocutionary force on their own, like the American broadcast tokens. One involves, similarly, speaker designation of one of two possible interlocutors (example 13):

13. "Thanks, Carrie." Seb's look returned to the farmer. "And thanks to you, too, Christian. It's going to work ... I know it" (HHC W fict prose)

The other echoes the previous speaker and emphasizes their change of role from thanksgiver to thanks-recipient, surprising in this context because the second speaker is the employer of the first (example 14): 
14. "Thanks again." "And thanks to you for giving Gareth such a good day yesterday." (ADY W fict prose)

The last token is from a historical novel and seems, like the statements which follow it, markedly formal and archaic (example 15):

15. The rider nodded, pulled the horse's head round. "My thanks to you. Perhaps we may meet again. Should you change your mind, the name is Clarkson." (C85W fict prose)

Given the paucity of these tokens, and the non-appearance of the broadcast formula in the BNC, it seems fair to conclude that thanks to you is extremely marked as an expression of gratitude in contemporary British spoken English.

\subsection{Thanks to you meaning "because of you"}

In addition to its use in expressions of gratitude, in both the American and British corpora thanks to you was used to communicate causality, the meaning that something had happened because of you. In COCA, these causality uses of thanks to you formed a large proportion of all instances in general conversation $(147 / 347=42 \%)$.

This causality use raises the issue of speaker attitude, or affect. In all the data tokens discussed so far, thanks to you has been judged by the researchers to either constitute or be part of an expression of gratitude rather than a complaint; as such the speaker is demonstrating positive affect. As is well known (Eisenstein \& Bodman 1986; Culpeper 1996), however, expressions of gratitude can be ironic, and hearers are required to make pragmatic judgments about speaker affect, e.g., whether a speaker is in fact performing the speech act of expressing gratitude or, on the contrary, via sarcasm expressing displeasure, complaining or insulting.

With the causality use of thanks to you, however, the situation is more complex. On an ideational level thanks to $X$ appears virtually synonymous with other adverbials of circumstance expressing causality, such as because of $X$, owing to $X$, due to $X$, on account of $X$, etc., where $\mathrm{X}$ is an action, circumstance, or agency. However, it appears to be the case that the thanks to formula also has an affective, interpersonal meaning, presumably carried over from its expression-of-gratitude meaning, conveying the speaker's evaluation of X. As with expressions of gratitude, irony is possible. If a speaker says "thanks to the UN", for example, the phrase could be indicating the speaker's pleasure or displeasure with the UN. Use of thanks to $X$ seems to invite the hearer to attend to the speaker's affective response to the circumstance being described in a way that other causality adverbials do not.

Recalling the universal view of the native speakers in the conference discussions mentioned above that thanks to you is always sarcastic, e.g., always indicates negative speaker affect, all instances of thanks to you classified as causality adverbials were therefore further analyzed to see whether they signaled positive or negative speaker affect (see Table 4). This judgment was based on an analysis of the context, to find whether the event or circumstance for which the speaker was assigning causality to the 
listener was likely to be regarded as positive or negative, for example, recovering from illness (positive) or failing an exam (negative). Contrary to the native speakers' intuition, analysis of COCA revealed that $62 \%(81 / 131)$ of the causality instances of thanks to you were in fact positive, leaving $38 \%$ negative.

It is also noticeable from Table 4 that the use of causality thanks to you in actual spoken usage (26) was much lower than its use in fiction dialogue (105). This perhaps suggests a greater concern with speaker affect in fiction than in talk radio and TV. However, as word counts for the dialogue sections of the fiction texts are not available (and thus normalized frequencies cannot be calculated) this hypothesis cannot be pursued here.

\begin{tabular}{|l|l|l|l|}
\hline & Positive & Negative & Combined \\
\hline $\begin{array}{l}\text { Fiction } \\
\text { dialogue }\end{array}$ & 62 & 43 & 105 \\
\hline Spoken & 19 & 7 & 26 \\
\hline Total & $\mathbf{8 1}$ & $\mathbf{5 0}$ & $\mathbf{1 3 1}$ \\
\hline
\end{tabular}

Table 4 Causality tokens of thanks to you by affect in COCA

In the BNC, the causality meaning of thanks to you was by far the most common usage, with 41 out of 44 being causality and only 3 being expressions of gratitude. As with the COCA results, causality tokens of thanks to you were much more frequent in fiction dialogues than in spoken texts (see Table 5). Positive affect instances formed a similarly large majority proportion of the whole (54\%).

\begin{tabular}{|l|l|l|l|}
\hline & Positive & Negative & Combined \\
\hline Fiction dialogue & 21 & 18 & 39 \\
\hline Spoken & 1 & 1 & 2 \\
\hline Total & $\mathbf{2 2}$ & $\mathbf{1 9}$ & $\mathbf{4 1}$ \\
\hline
\end{tabular}

Table 5 Causality tokens of thanks to you by affect in BNC

\subsection{Position of causal thanks to you in relation to effect}

Causality necessitates a cause and an effect, either of which may be stated first. In causality uses, in both COCA and BNC, thanks to you always indicates the cause (action by the addressee - "you"): the corresponding effect may be stated either before or after this cause. Another variable which was analyzed for causal tokens of thanks to you, therefore, was whether thanks to you occurred before or after the statement of effect. These options are exemplified in 16 and 17, respectively:

16. "I'm the last person they're ready to listen to right now [EFFECT]. Thanks to you [CAUSE]." (FIC: Mov: PointBreak) 
17. "We have enough of both, thank you. And now... thanks to you [CAUSE], we have exposure [EFFECT]. I don't like exposure." (FIC: Mov: Crow3)

The thanks to you token sometimes comes in the middle of the effect, as in the following COCA example (effect indicated in italics):

18. "We have very well documented reports, thanks to you in the news media, of perhaps a lot of mobilization..." (SPO: NBC_Today)

Let us note that in many cases of positive affect (e.g., example 18), what has been designated here as causal use of thanks to you appears close to being a "regular" expression of gratitude. As other corpus research has shown (Schauer \& Adolphs, 2006), giving a reason for gratitude is a common accompanying move in spoken English. However, with thanks and thank you the reason move is optional. With causality instances of thanks to you, the reason move is obligatory: the speaker signals explicitly that the reason for his/her affective state is the link between cause (action by the addressee - "you") and a particular effect. While in practice, in cases where the speaker's affective state is positive, thanks to you will often express gratitude, in cases where the speaker's affective state is negative it will express, rather, blame. This is why, in the authors' estimation, the primary function of this use of thanks to you should, like other thanks to $X$ phrases, be conceptualized as being to indicate (a) causality and (b) speaker attitude to this causality, rather than to express gratitude.

Overall, as Table 6 shows, there seems to be a general tendency for thanks to you as cause to appear about twice as often after rather than before effect, in instances of both positive and negative affect. To summarize, then, the evidence would suggest that positioning of thanks to you, e.g., the position of the phrase in relation to the statement of the effect for which the addressee is being thanked, does not in itself serve as a signal of whether speaker affect is positive or negative.

\begin{tabular}{|l|l|l|l|l|}
\hline Affect & $\begin{array}{l}\text { Precedes } \\
\text { effect }\end{array}$ & In the middle & Follows effect & Combined \\
\hline Positive & 37 & 5 & 61 & 103 \\
\hline Negative & 17 & 3 & 46 & 66 \\
\hline Total & 54 & 8 & 107 & 169 \\
\hline
\end{tabular}

Table 6 Positioning of all causality tokens of thanks to you by affect

As shown in Table 7, this distribution applies to both corpora.

\begin{tabular}{|l|l|l|l|l|}
\hline Corpus & $\begin{array}{l}\text { Precedes } \\
\text { effect }\end{array}$ & In the middle & Follows effect & Combined \\
\hline COCA & 41 & 7 & 83 & 131 \\
\hline BNC & 13 & 1 & 24 & 38 \\
\hline
\end{tabular}




\begin{tabular}{|l|l|l|l|l|}
\hline Corpus & $\begin{array}{l}\text { Precedes } \\
\text { effect }\end{array}$ & In the middle & Follows effect & Combined \\
\hline Total & 54 & 8 & 107 & 169 \\
\hline
\end{tabular}

Table 7 Positioning of all causality tokens of thanks to you by corpora

Examples 16 and 17 are instances of negative affect but the following (examples 19 and 20), like example 18, are from positive affect instances, before and after, respectively:

19. said Farmer Olinton grimly. "Mrs. Olinton's rung the fire-brigade, but, thanks to you, young lady, it doesn't look as if we're going to need it.." (B0B W_fict_prose)

20. “How's your dad doing?" “Fine, thanks to you.” (FIC: Bk: PlaceBelong)

One pattern which appeared in COCA in four instances but not the BNC was that positive thanks to you occurred in response to a question. These tokens implicitly answer the question in the affirmative as well as indicate causality. (See example 21.)

21. Andy demanded, "You O.K.?" "Thanks to you guys." Zach drew a shaky breath. (FIC:Boys' Life)

\subsection{No thanks to you and small thanks to you}

In COCA, one particular manifestation among the 37 negative uses of thanks to you following the effect was that in 15 instances the token was preceded by no with a variation, small, occurring once. Following are examples of no thanks to you and small thanks to you (see examples 22-23). Although, like unmodified thanks to you tokens these are also complaints, they are not ironic: they explicitly express the speaker's dissatisfaction with the interlocutor's failure to cause what is presented as a benign effect:

22. "How? Like I always have. By hook or by crook. No thanks to you." Then she said, "What do you care?" (FIC: Southwest Rev)

23. "I got glory. I got all there is, and small thanks to you, squire." (FICTION: Mov: Gangs New York)

In the BNC "small thanks to you" was not used, but there were three instances of no thanks to you (see example 24).

24. "are, Leonora. I see you've met my mother." "No thanks to you," said Mrs Vaughan in dry reproof. (JYC W_fict_prose) 


\subsection{Address forms accompanying causal thanks to you}

Personal names as forms of address (italicized) in COCA occurred in seven positive instances of thanks to you (as in examples 25-26) but not once in the negative uses. Six of these seven uses of personal names occurred in fiction, with the one actual spoken use appearing on CBS_Morning. This use of personal names, only with positive thanks to you, also occurred once in the BNC. (See example 26.)

25. "Thanks to you, Harry, I got my weekends planned for the next three months" (SPOKEN: CBS_Morning)

26. "Of course it is. I'm a free spirit, thanks to you, Miguel. And yes, I know I'm beautiful, if" (JYA W_fict_prose)

Overall, titles/positions/relationship terms of address (rector, friend, son, sir) were used in four positive instances in American usage and seven times in the BNC (address forms italicized, example 27, COCA; example 28, BNC).

27. "And quite well, it seems. Thanks to you, son. Thanks to you all." (FIC: Mov: BatmanRobin)

28. "looking back on the hill there, I saw him in the valley. But thanks to you, sir," he leaned out and took Hope's right hand between his palms and pressed it, "thanks to you, I believe we are safe." (19 FP1 W_fict_prose)

Personal names as forms of address were not used in "regular" negative instances of thanks to you in COCA. There was only one use of a title (squire in example 23) in negative use of thanks to you. Insults (you murderer and creep) were used as forms of address in two negative uses, for example:

29. "The hoorklas didn't rip you to shreds." "No thanks to you, creep," I muttered. He ignored that. (FIC: BkSF: TemptationsSt)

In the BNC as well, with negative use of thanks to you, the name of the person being addressed was not used. This is perhaps unsurprising because terms of respect or intimacy, usually associated with positive face, would not accord with the intentional impoliteness or face-threatening nature of using thanks to you negatively.

\section{Discussion}

Corpus analysis suggests that thanks to you in contemporary spoken American and British English is seldom found in academic settings: no use was found in MICASE, or the spoken academic component of the BNC. The most frequent use of thanks to you in the American corpus was as a broadcast formula used by radio/television talk show hosts and news anchors when thanking guest speakers and journalists for joining the program, 
as well as thanking viewers at home for listening to the program. This broadcast formula did not appear in the British corpus. Analysis of COCA and the BNC yielded a very small sample of tokens which functioned to express gratitude. The remaining use of thanks to you in the American corpus and its largest use by far in the British corpus was to indicate causality (e.g., "because of you") in such a way as to also signal speaker affect, both positive and negative.

One of the striking features of thanks to you is its embeddedness in particular contextual settings: in most cases, as we have seen, it is not just a synonym for the more widely used gratitude expressions "thank you" and "thanks". It is not - as language learners might falsely assume, on the general principle that longer is politer - a more polite or more elegant variant of "thank you".

Although the proportion of thanks to you tokens expressing sarcasm is lower than that intuited by the native English speakers in the conference discussions mentioned earlier, it is relatively large, making the potential for problematic pragmatic miscommunication with the expression quite high. Communicating "because of you" sarcastically instead of expressing gratitude is a much more serious miscommunication with social implications than, for example, saying "welcome" instead of "you're welcome" in response to someone's "thank you" in that with thanks to you the intended politeness may be interpreted as intentional impoliteness.

Analysis of the American and British corpora provides useful insight for the teaching and testing of use of thanks to you to English language learners, both in the USA and in lingua franca situations. In particular, the corpora provide valuable examples of actual language use which teachers and students can use to identify typical sentence patterns using thanks to you as an expression of gratitude and to indicate causality, both to compliment (thanks to you) and to rebuke, either directly (no thanks to you) or sarcastically (thanks to you).

First, corpus analysis shows that it is important to teach the different meanings of thanks to you, in particular the frequently occurring causality meaning that can be either polite or sarcastic. Language learners whose first languages include polite use of an expression similar to thanks to you (such as in Arabic and Spanish) would greatly benefit from explicit instruction in order to avoid negative transfer. Also, while most language learners are unlikely to need to use thanks to you as a broadcast formula, such usage is an expression of gratitude, and learners would benefit from knowing that thanks to you is only infrequently used as expression of gratitude, and then in relatively formal circumstances.

Second, in light of the potential for pragmatic failure in misuse of thanks to you, language learners need to be taught the importance of contextualization in use of this expression. One aspect of contextualization of causal thanks to you is how this expression can precede, follow, or be in the middle of additional words which would make its intended meaning clear for listeners, although the middle placement structure is much less common than the other two positions. It would be helpful if textbook writers, in addition to samples of real-world communication using thanks to you, would provide examples for learners of specific conversational structures to use in contextualizing thanks to you, such as the following which reflect the two most common placement positions: 
"[Positive/negative effect statement], thanks to you"

"Thanks to you, [positive/negative effect statement]"

The third, less common structure is when thanks to you is placed in the middle of the effect statement, with a portion of the effect statement continuing after thanks to you, as in the following:

"[Positive/negative effect statement], thanks to you, [continuation of positive/negative effect statement]"

Another conversational structure in causal use of thanks to you is when two speakers carry out an exchange which can be positive or negative, as follows:

Speaker 1: "[Positive statement]."

Speaker 2: "Thanks to you."

Speaker 1: "[Positive acknowledgment]."

Speaker 1: "[Negative statement]."

Speaker 2: "Thanks to you."

Speaker 1: "[Negative acknowledgment]."

A third aspect of pragmatic implications with contextualization of thanks to you seen in both British and American usage is that when used negatively, the sarcastic meaning of this expression precludes the use of personal names. However, titles and forms of address were used with negative causal thanks to you.

It seems unlikely that language instructors would need to instruct learners how to produce sarcastic utterances, but alerting advanced learners to the possibility of irony, whether playfully humorous or bitingly sarcastic, in language they process would be useful in preventing socially charged pragmatic failure.

In classroom instruction and assessment of use of thanks to you, sufficient context would need to be provided so that students would be able to determine the intended meaning. Concerning contextualization, Cohen (2008: 220) raises a question about context provided in pragmatics discourse completion tasks (DCTs): "to what extent can we create a viable situational context by means of a single prompt?" Fishman's (1972) sociolinguistic parameters provide helpful guidelines for contextualization of social interaction, including indication of the domain, the interlocutors and their relationships, the setting, and the purpose of the communication. Rose (1992) contextualized discourse completion tasks to assess pragmatic knowledge, indicating the communicative goal, social distance between interlocutors, and social dominance. Varghese and Billmyer's (1996) study added more extensive contextualization, including more detailed information about the interlocutors, their relationship, and the setting. However, Roever (2004) describes a likely challenge in the construction of longer prompts for test items. In other words, too extensive contextualization would take up test time for students to read and could raise questions about how well they understand the extensive test item prompt. Nevertheless, in both instruction in and assessment of the pragmatics of use of 
thanks to you, it is necessary to provide sufficient explanation in order for students to be able to discern the meaning of thanks to you as used in class activities or test items in which they are required to identify the intended illocutionary force (gratitude, positive or negative affect causality). As Schauer and Adolphs (2006) argue, corpus-inspection can help remedy the inevitable limitations of native-speaker intuition as solicited by DCTs and lead to the design of more effective DCTs and teaching materials. Class activities such as having students write and discuss literal translations of cognate gratitude formulas - such as shukran lakum in Arabic or gracias a ti in Spanish - in response to DCT prompts (Eslami-Raskh 2005) would also be useful in raising learner's awareness that these are "false friends".

In terms of effective intercultural communication in English-as-a-lingua-franca (ELF) situations where the majority of speakers are not native speakers of English or are speakers of different varieties of English, particularly in regions where some speakers' first language includes known false friends used to communicate gratitude, use of thanks to you should be viewed particularly carefully. In intercultural ELF communication, to be effective, speakers need to be flexible and seek to understand an interlocutor's intended meaning, recognizing possible effects of first language influence and realizing that people of varying levels of English ability may be using whatever English words are available to them, and not always in accordance with the standards of a native-speaker English dialect. In a sense, hearing ELF communication containing a pragmatically loaded expression such as thanks to you can be more challenging for highly skilled English speakers (native or non-native) who are more sensitive to the pragmatic implications of word choice, because they may need to set aside their reactions to perceived misuse of such an expression by another user of English who happens to be unaware of the possible negative associations of this phrase.

\section{Conclusion}

Let us return briefly to the opening anecdote which stimulated this investigation. Based on the above analysis of corpus data, we can see more clearly how the native Arabic speaker's contribution was a pragmatic failure. We cannot know the speaker's real intention but let us begin by hypothesizing that his intention was to express gratitude. In this case, his utterance failed because, in terms of the felicity conditions required for successful performance of the illocutionary act of thanking (Austin 1962) the speaker failed to make the hearers aware of the particular act for which he wished to thank them. Such an act had not occurred immediately in the prior context, and he did not proceed to state what it was (for example, "Thanks to you all for your help with my report"). In this respect, even had the speaker used a more common expression of gratitude such as thank you or thanks, the illocution would have been incomplete. The absence of other contextual features which we have seen to be normally associated with the gratitude use of thanks to you - using the phrase as part of a larger explicitly performative verb phrase, thanking on behalf of a larger group, thanking in front of a third party, disambiguating the intended recipient(s) from others within earshot, returning thanks to a speaker who has just thanked the hearer - may have taken time for the hearers to process and simply have added to the confusion created by the utterance. 
Let us now consider an alternative hypothesis: that the speaker intended to indicate causality and express his attitude to that causality. As with thanking, the utterance is incomplete: there was no effect in the immediately prior context to which thanks to you could be understood as assigning a cause, nor did the speaker proceed to state one (for example "Thanks to you, my report went well" or "Thanks to you, I wasn't able to finish my report on time"). Even though he was smiling as he used this expression, we can suppose from the high incidence of sarcasm in American usage of thanks to you that the phrase could very likely have given this speaker's listeners reason to suppose that he was on the point of blaming them for an adverse consequence, and was in fact mocking them. This could have led to the awkward silence and failure to initiate repair (for example, "Well thanks, but what are you thanking us for?" or simply, "For what?") on the part of the listeners.

Let us now consider a third alternative hypothesis, bearing in mind that in all three cases this speaker made the utterance prior to leaving: this hypothesis would be that the speaker intended the expression as valediction or formal leave-taking. As we have seen, in many instances of thanks to you as a broadcast formula, the phrase serves in part as a near synonym for goodbye and it seems possible that the speaker having heard it on the media could have mistakenly assumed that it was a general polite formula for leavetaking.

Whatever the speaker's intention, the listeners' uncertainty as to his intended meaning almost certainly contributed to their lack of response to his utterance, resulting in a "noticeable and accountable" (Dippold 2008: 138) absence of the second pair part of a gratitude-response adjacency pair, a causality-acknowledgment adjacency pair, or a farewell adjacency pair. It is to be hoped that corpus research of the kind described in this paper will lead to improved descriptions of the pragmatics of everyday interactions and further that, equipped with such descriptions, language instructors and assessors will be able to produce materials which help learners to avoid such communication failures and their socially adverse consequences.

\section{References}

Alosh, Mahdi. 2000. Ahlan wa Sahlan: Functional Modern Standard Arabic for Beginners. New Haven, CT: Yale University Press.

Appadurai, Arjun. 1985. "Gratitude in South India.” Ethos, 13 (3): 236-245.

Austin, John L. (1962). How to Do Things with Words. Oxford: Oxford University Press.

Bachman, Lyle F. and Adrian Palmer. 1996. Language Testing in Practice. Oxford: Oxford University Press.

Bonvillain, Nancy. 1997. Language, Culture, and Communication: The Meaning of Messages ( $2^{\text {nd }}$ Ed.). Upper Saddle River, NJ: Prentice-Hall.

Cohen, Andrew D. (2008). "Teaching and assessing L2 pragmatics: What can we expect from learners?" Language Teaching, 41 (2): 213-235.

Culpeper, Jonathan. 1996. "Towards an anatomy of impoliteness." Journal of Pragmatics 25, 349-67.

Davies, Mark. 2004-. BYU-BNC: British National Corpus. Retrieved June 7, 2010, from http://corpus.byu.edu/bnc/ 
Davies, Mark. 2008-. The Corpus of Contemporary American English (COCA): 400+ million words, 1990-present. Retrieved March 3, 2010, from http://www.americancorpus.org/

Dippold, Doris. 2008. "Reframing one's experience: Face, identity and roles in L2 argumentative discourse." InMartin Putz and JoAnne Neff-van Aertselaer (eds.) Developing Contrastive Pragmatics: Interlanguage and Cross-cultural Perspectives, 131-154. Berlin: Mouton de Gruyter.

Eisenstein, Miriam and Jean Bodman. 1986. “'I very appreciate': Expressions of gratitude by native and non-native speakers of American English." Applied Linguistics, 7 (2): 167-185.

Eisenstein, Miriam and Jean Bodman. 1993. "Expressing gratitude in American English.” In Gabriele Kasper and Shoshana Blum-Kulka (eds.) Interlanguage Pragmatics, 64-81. Cary, NC: Oxford University Press.

Eslami-Rasekh, Zohreh. 2005. "Raising the pragmatic awareness of language learners." ELT Journal 59 (3): 199-208.

Fishman, Joshua A. 1972. Domains and the relationship between micro- and macrosociolinguistics. In John J. Gumperz and Dell Hymes (eds.) Directions in Sociolinguistics, 435-453. Oxford: Blackwell.

Gesuato, Sara. 2007. "How (dis)similar? Telling the difference between near-synonums in a foreign language. In Encarnación Hidalgo, Luis Quereda, and Juan Santana (eds.) Corpora in the Foreign Language Classroom: Selected Papers from the Sixth International Conference on Teaching and Language Corpora (TaLC 6), 175-190.

Hunston, Susan. 2002. Corpora in Applied Linguistics. Cambridge: Cambridge University Press.

Hutchby, Ian and Ron Wooffitt. 1998. Conversation Analysis. Cambridge: Polity.

Intachakra, Songthama. 2004. "Contrastive Pragmatics and Language Teaching: Apologies and Thanks in English and Thai." RELC 35.(1): 37-62

Jacobsson, Mattias. 2002. "Thank you and thanks in Early Modern English." ICAME Journal 26, 63-80.

Johns, Tim. 1991. "Should you be persuaded - two samples of data-driven learning materials." In Tim Johns \& Philip King, 1991 (eds.) "Classroom Concordancing”. ELR Journal 4, 1-16.

Kasper, Gabriele and Carsten Roever. 2005. Pragmatics in second language learning. In Eli Hinkel (ed.) Handbook of Research in Second Language Learning and Teaching, 317-384. Mahwah, NJ: Lawrence Ehrlbaum Associates

Kasper, Gabriele and Kenneth R. Rose (eds.). 2001. Pragmatics in Language Teaching. Cambridge: Cambridge University Press.

Keck, Casey. 2004. "Corpus linguistics and language teaching research: bridging the gap.” Language Teaching Research 8 (1): 83-109.

Lanteigne, Betty. 2007, November 2. "Using sociolinguistic parameters to contextualize test tasks." 11th Annual Current Trends in English Language Testing, Dubai, UAE.

Lanteigne, Betty. 2009, March 12. "Using sociolinguistic parameters to contextualize test tasks." TESOL Arabia. Dubai, UAE.

McNamara, Tim and Carsten Roever. 2006a. Language Testing: The Social Dimension. Malden, MA: Blackwell. 
McNamara, Tim and Carsten Roever. 2006b, December. "The social dimension of proficiency: How testable is it?" Language Learning, 56, 1-255.

Nelson, Gayle, Mahmoud Al-Batal and Erin Echols. 1998. "Arabic and English compliment responses: Potential for pragmatic failure." Applied Linguistics, 17 (4): 411-432.

Nofsinger, Robert E. 1999. Everyday Conversation. Prospect Heights, IL: Waveland Press.

Reinhardt, Jonathan. 2010. "The potential of corpus-informed L2 pedagogy." Studies in Hispanic \& Lusophone Linguistics, 3 (1): 239-251.

Roever, Carsten. 2004. "Difficulty and practicality in tests of interlanguage pragmatics." In Diana Boxer and Andrew D. Cohen (eds.) Studying Speaking to Inform Second Language Learning, 283-301. Clevedon: Multilingual Matters.

Rose, Kenneth R. 1992. "Speech act research and written questionnaires." Journal of Pragmatics, 17, 49-62.

Schauer, Gila and Svenja Adolphs. 2006. "Expressions of gratitude in corpus and DCT data: Vocabulary, formulaic sequences, and pedagogy." System 34 (1): 119-134

Schegloff, Emanuel. 1968. "Sequencing in conversational openings." American Anthropologist, 70 (6): 1075-1095.

Searle, John R. 1969. Speech Acts: An Essay in the Philosophy of Language. Cambridge: Cambridge University Press.

Singh,Rajendra, Jayant Lele, and Gita Martohardjono. 2005. "Communication in a multilingual society." In Scott F. Kiesling and Christina Bratt Paulston (eds.) Intercultural Discourse and Communication: The Essential Readings, 45-57. Oxford: Blackwell.

The University of Michigan English Language Institute. 2007, June 13. Michigan Corpus of American English. Retrieved March 3, 2010, from http://quod.lib.umich.edu/m/micase/

Thomas, Jennifer. 1983. "Cross-cultural pragmatic failure." Applied Linguistics, 4 (2): 91-112.

Wong, May L.-Y. 2010. "Expressions of gratitude by Hong Kong speakers of English: Research from the International Corpus of English in Hong Kong (ICE-HK)." Journal of Pragmatics 42, 1243-1257.

Varghese, Manka and Kristine Billmyer. 1996. "Investigating the structure of discourse completion tests." Working Papers in Educational Linguistics, 12, (1): 39-58.

\section{About the Authors}

Betty Lanteigne ( $\mathrm{PhD}$ - Indiana University of Pennsylvania - sociolinguistics/language assessment/cross-cultural communication) has taught ESL/EFL in the USA, UAE, Palestine, Qatar, Kuwait for 16 years, developed an IEP and an English education B.A., and as a Fulbright Fellow, investigated non-Western English to address culturally inappropriate language assessment. Member of Phi Kappa Phi, Pi Lambda Theta, International Association of Language Testers and TESOL, she has presented about language assessment and sociolinguistics and is affiliated with Language Assessment and Sociolinguistics Department of English American University of Sharjah, UAE. 
Peter Crompton ( $\mathrm{PhD}$ - University of Lancaster, UK - text analysis/corpus linguistics/academic writing) has taught EFL, EAP, and applied English linguistics at universities and colleges in China, Saudi Arabia, Brunei, Lithuania, the UK, and the UAE. $\mathrm{He}$ has published and presented in the areas of interaction in academic writing, Business English, intercultural rhetoric, written text structure, and the application of corpus linguistics to language learning. 